\title{
TRES MODOS PARA EVADIR LA «CURIA» COMBATIDOS POR JULIANO (C. Th., XII, 1, 50)
}

\author{
JUAN JOSE CHAO FERNANDEZ \\ Universidad de Alicante
}

\begin{abstract}
La constitución C. Th., XII, 1, 50, de 13 de Marzo de 362, forma parte de una serie de medidas tomadas por Juliano en Constantinopla a fin de dotar a las ciudades de medios con los que hacer frente a todos los servicios que cumplían en el Bajo Imperio. Se compone de tres partes claramente diferentes, que son otras tantas medidas para impedir nuevos tipos de evasión de las cargas de la curia que aparecen a mediados del siglo IV: huida de los clérigos cristianos por los privilegios concedidos por los hijos de Constantíno, que llevan a ordenaciones masivas de curiales; ejercicio del comercio a gran escala por parte de los curiales sin abonar la collatio lustralis. Juliano eximirá de su pago a los curiales que no ejerzan el comercio o se limiten al minorista. Y finalmente la huida al patronazgo de un potens.
\end{abstract}

The constitution C.Th., XII, 1,50 of March $13 \mathrm{th}, 362$, is one of a series of measures taken by Julian in Constantinople to provide the cities with everything necessary to meet the services required of them in the Later Empire. It consists of three distinct parts, serving as additional measures to prevent new methods of evading the duties of the curia that appear towards the middle of the 4th century; the flight of christian clergy as a result of privilegies conceded to them by Constantine's children $\&$ the consequent massive ordenation of curiales; large-scale commerce practised by curiales without paying the collatio lustralis. Julian exempts from payment those curiales not engaged in commerce or who restrict themselves to retail practice. And finally the flight from patronage of a potens.

Las diversas maneras de evitar la curia comienza a fijarse desde la crisis del siglo III, al hacerse las cargas (munera) y cargos (honores) demasiado pesados y al tratar los curiales (decuriones) de escapar de ellas. La contrapartida no se hará esperar. Las funciones de la curia se convierten en hereditarias (1). En el primer tercio del siglo IV las constituciones de Constantino, conservadas en el $\mathrm{Co}$ dex Theodosianus, al prohibirlos, especificarán los diversos modos de huir de las cargas curiales: concesión de inmunidades por el gobernador de la provincia o la misma ciudad a algunos de los miembros de la asamblea de las ciudades; alegaciones de origo et incolatus; abandono de las obligaciones curiales refugiándose en los officia de los gobernadores, en el ejército o en la clase senatorial;

1) C. Th., XII, $1,13(326) ; 14$ y 18 [(326 (353 Mommsen, pero véase GAUDEMET, 1951, 60, n. 78, y 63-64, n. 90: «Piganiol, 1947, 536, pense que l'héredité curiale «a été précisé vers 320»)]. JONES, 1964, II, 724-766. GAUDEMET, 1967, 707-709. 
e incluso el recurso al matrimonio con mujer esclava (2). Siguiendo la política de su padre, Constancio dedicó una veintena de constituciones a la represión de la evasión de la curia $(C . T h ., X I I, 1,14 ; 18 ; 23 \ldots 48)$. Así pues esta constitución del emperador $\mathrm{Fl}$. Cl. Juliano se inserta, desde este aspecto, en la política general que los diversos emperadores del siglo IV mantendrían, como más adelante veremos.

La constitución $C$. Th., XII, 1, 50: IMP. IVLIANVS A. SECVUNDO P(RAEFECTO) P(RAETORI) O.-POST ALIA: Decuriones, qui ut Christiani declinant munia, revocentur. Et ab auri atque argenti praestatione, quod negotiatoribus indicitur, curiae immunes sint, nisi forte decurionem aliquid mercari constiterit, ita ut ordines civitatum ex huiusmodi reliquis sarcinarum, ut iam diximus, amoveantur. Et quoniam ad potentium domus confugisse quosdam relatum est curiales, ut tam foeda perfugia prohibeantur, multam statuimus, ut per singula capita singulos solidos dependat, qui ad potentis domum confugerit et tantundem qui receperit multae nomine inferat. Nam si servus inscio domino susceperit, capite punietur, et ingenuus, qui invito patrono hoc fecerit, deportabitur. P(RO) P(OSITA) III ID. MAR. CONS(ANTINO) P(OLI) MAMERTINO ET NEVITTA CONSS.

Esta constitución forma parte de un conjunto de medidas que aparece en Constantinopla el 13 de marzo del año 362, según nos enseña la subscriptio, encaminado a sanear la economía de las ciudades devolviéndoles tanto sus bienes y aquellos de los templos expoliados por Constantino y Constante, como las personas que por su solvencia económica fueran capaces de contribuir al mantenimiento de las ciudades (3). El carácter de la misma debió ser general para todo el imperio, como se deduce de que la constitución $C$. Th., $X I, 23,2$ haya sido conservada por el Codex en copia dirigida a Salustio, Prefecto de Pretorio de las Galias y España, mientras que las demás, por copias dirigidas a Secundo, Prefecto de Pretorio de Oriente, e igualmente por el entusiasmo que estas medidas despertaron a lo largo de todo el imperio, especialmente en Africa y Palestina, testimoniado por el texto de las inscripciones halladas en estos lugares (BIDEZ, 1965, 228-229; ARCE, 1975, a, 340 y ss.; 1975, b, 38).

En la misma línea se nos ha conservado la carta de Juliano a los Byzanze-

2) INMUNIDADES: Ulpiano, D. 50, 5, 1; 9, 4, 1 Diocleciano, C. I. $X, 32,13$, y 47, 1 y 2 Constantino. C. Th., $X I I, l, l$ (326). CLERIGOS: $C$. Th., $X V I, 2,6$ y 3 (329). ORIGO ET INCOLATUS: $C$. $T h$., $X I I, 1,12(325)$, OFFICIA ET MILITIA: $C$. $T h ., X I I, 1,12(325) ; 13(326)$ y 22 (336). HONORES: $C$. Th., $X V I, 1,14$ [326 (353 Mommsen)] y 18 [329 (353 Mommsen)], si son de Constantino, que GAUDEMET, 1951, 60 piensa que sí. JONES, 1964, III, 236, n. 65, piensa que lo más probable es que sean de Constancio, siguiendo a Mommsen. CONTUBERNIUM: $C$. Th., XII, 1,6 [319 (318 GAUDEMET)]. GAUDEMET, 1951, 54-65 y 73-75 para estos problemas.

3) C. Th., X, 3, $1 ; X I, 16,10 ; X I, 23,2 ; X I I, 1,50$, y XIII, 1, 7. Ya Godofredo vio que eran parte de una sola constitución separada por los recopiladores. (GODOFREDO, 1665, IV, 361). 
nos, que Bidez data con posterioridad a ésta, y cuyo texto tiene una mayor comprensión (4).

La constitución que nos ocupa se compone de tres partes claramente diferenciadas, como la inclusión de las dos primeras partes en otro lugar del Codex pone de manifiesto $(C$. Th., $X I I I, 1,4)$. La primera parte restituye a la curia los decuriones que habían entrado a formar parte de los clérigos cristianos para escapar así a la curia. La segunda exime a los curiales que no desarrollan actividad comercial considerable de la collatio lustralis, al tiempo que condona los atrasos. Finalmente la tercera trata de impedir que el curial se beneficie del patronazgo de un potens para evadir la persecución de la curia o del Imperio (5).

\section{Restitución de los clérigos cristianos}

Esta constitución no tiene un carácter anticristiano, como a primera vista podría parecer, según puede deducirse tanto de su temprana fecha (6) como de la consideración aséptica de la época y de las leyes que al respecto dieron los emperadores posteriores (7), sino que está inspirada en el afán de devolver a las ciudades su antiguo esplendor.

a) Antecedentes de la constitución.

Las conversaciones de diciembre de 312 o febrero de 313, en Milán, entre Constantino y Licinio, dieron paso a una política de tolerancia religiosa que se va a materializar en la carta de Constantino al procónsul de Africa, Anulino, en marzo-abril y en el edicto publicado en Nicomedia por Licinio, que, de hecho, concedían la libertad de culto a la Iglesia y le devolvían los bienes confiscados (8).

La política liberal de Constantino le lleva, al tener en cuenta las costumbres de los cristianos, a suprimir algunas leyes vigentes como la lex Iulia de maritandis ordinibus, todavía en vigor, contraria a las prácticas cristianas del celibato y

4) JULIANO, 1932, I, 2, 66.

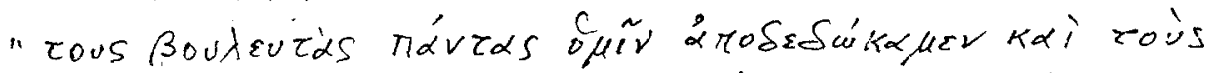

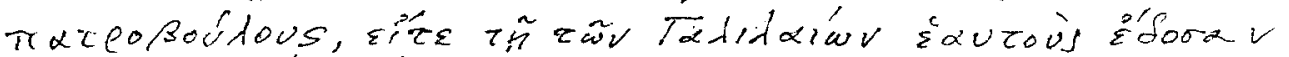

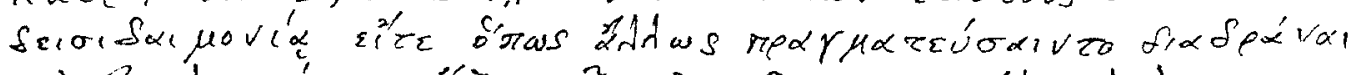

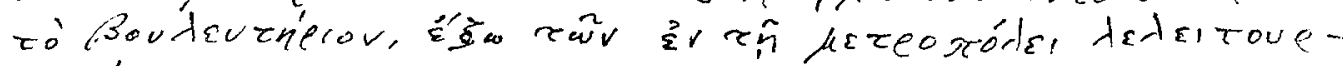

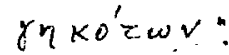

5) GAUDEMET, 1951, 74-75. MARTROYE, 1928, 201-248, cita $C$. Th., $X I, 24, I$ (360), como primera indicación de patrocinium. Si textualmente tiene razón, los indicios indirectos parecen dar la razón a la hipótesis de GAUDEMET, 1951, 74-75.

6) BIDEZ, 1965, 228 y 227-230. LACTANTIUS, De morte persecutorum, 48. EUSEBIO DE CESAREA, $H . E ., X, 5,2-14$ y 15-17. MESLIN - PALANQUE, 1967, 206-208.

7) C. Th., XII, 1, 59 + XVI, 2, $17(364) ; X V I, 2,19(370) ; 21$ (371);C. Th., XII, 1, $104(383) ; 115$ (386); 121 (390), y 123 (391). DECLAREUIL, 1904, 324-327. GAUDEMET, 1958, 145 ss. PIGANIOL, $1972^{2}$, 149. BROWNING, 1975, 132. BOWERSOCK, $1980^{2}$ (1978), 74.

8) CHASTAGNOL, 1969, 43-47. JONES, 1964, I, 80 ss. GAUDEMET, 1958, 9-11, y sobre la fecha en diciembre de 312 o febrero de 313 (cf. 10, notas 6 y 7). PALANQUE, 1935, 607-612, propone una fecha conciliadora: enero 313. FONTAN, 1974, 168, lo retrasa a junio del 313 (basándose en EUSEBIO, H. E., $\mathrm{X}, 7)$, por lo que atribuye las medidas a la cancillería de Constantino. 
la virginidad (9), y a reconocer el carácter legal de sus instituciones. Así se les concede a las iglesias la capacidad de recibir legados, incluso por causa de muerte, pese a la prohibición de legar mortis causa a incertae personae, y se reconoce el carácter inhábil del domingo (10). Pero pronto derivará a una legislación de privilegio hacia la Iglesia, influido probablemente por su conversión. (GAUDEMET, 1958, 11. JONES, 1964, I, 89 y 91. Contrariamente REMODON, 1964, 146).

Entre otros privilegios autoriza a los obispos y clérigos, en la constitución del 321 dirigida a Osio, obispo de Córdoba, a manumitir esclavos, privilegio limitado hasta este momento a los gobernadores provinciales (11), y más tarde en 333 , concede que una causa judicial pueda ser trasladada a la jurisdición del obispo y que su decisión sea inapelable y ejecutada por las autoridades civiles. (Const. Sirm. I (333). JONES, 1964, I, 91 y C. Th., XVI, 2, 12 (355) y XVI, 2, 14 (357) de Constancio).

b) Exención de la curia.

Jones remonta la ley de exención de la curia de los clérigos cristianos al invierno siguiente a la batalla de Pons Milvius (JONES, 1964, I, 78 y 79; III, 13, n. 24. GAUDEMET, 1958, 177. FONTAN, 1974, 163 y 168). Aun en el caso de que las constituciones $C$. Th., XVI, $2,1,(313$ (21 de oct.) y $2(319,313)$ fuesen restringidas a Africa y a Lucania y Brutio su extensión a otras partes del Imperio se da como supuesta en $C$. Th., XVI, 2, 6, de 1 de junio, dirigida a Ablavio, Prefecto de Pretorio, probablemente de Italia (JONES-MARTINDALE-MORRIS, $1971,3)$ y en la 3 , de 18 de julio, a Baso, Prefecto de Pretorio de Oriente, ambas del año 329 (12), que precisamente restringen la limitación de ese privilegio y que, en opinión de Piganiol (cit. en GAUDEMET, 1951, 56, y n. ${ }^{\circ} 55$ ), son debidas a la entrada masiva de los curiales ricos en el clericato, para huir, de este modo, de las cargas fiscales de la ciudad.

En la constitución 6 , Constantino precisa neque vulgari consensu neque quibuslibet petentibus sub specie clericorum a muneribus publicis vacatio deferatur, sed cum defunctus fuerit clericus, ad vicem defuncti alius allegetur. Pero éste debía de cumplir dos condiciones: no ser de origen curial, ni poseer riquezas necesarias al Estado, como se desprende de la continuación de la propia constitución: Cui nulla ex municipibus prosapia fuerit neque ea est opulentia facultatum, quae publicas functiones facillime queat tolerare, ita ut si inter civitatem et clericos, super alicuius nomine dubitetur, si eum aequitas ad publica trahat ob-

9) C. Th., VIII, 16, I (320). GAUDEMET, 1967, 691. JONES, 1964, I, 92. REMODON, 1964, 146. CHASTAGNOL, 1969, 49. Pero GAUDEMET, 1958, 198, no cree en la influencia del pensamiento cristiano en esta constitución: «Les constitutions de 320 n'est-elle pas l'aveu d'une échec législative, l'abandon d'une position que dès l'Empire païen avait été bien difficile à tenir? Si elle profita aux chrétiens, ce ne fut peut-être qu'indirectement. Il n'en reste pas moins que les clercs benéficièrent de la même».

10) Sobre el domingo: $C$. Th., $I I, 8,1$ (321). JONES, 1964, I, 81, pone de manifiesto el carácter ambiguo de esta constitución. GAUDEMET, 1958, 293 ss. y 311 ss. GAUDEMET 1967, 700.

11) GAUDEMET, 1958, 11. JONES, 1964, I, 91, y, sobre todo, C. Th., IV, 7, 1 (321) Constantino. Texto importantísimo e indudablemente introduce una situación de privilegio al conceder la manumisión in conspectu ecclesiae con pleno estatuto de libertad como los procedimientos por vindicta, testamento o fideicomiso, mientras que los otros procedimientos de la época (inter amicos, per epistulam y per mensam) solamente proporcionaban la latinidad julia. Pero este modo tuvo una extensión bastante lenta (GAUDEMET, 1967, 718 ss.). n. 54 .

12) Sobre la corrección del orden de las constituciones y fechas véase GAUDEMET, 1951, 55 y 
sequia et progenie municeps vel patrimonio idoneus dinoscetur, exemptus clericis civitati tradatur.

Concluye, resumiendo claramente:

Opulentos enim saeculi subire necessitates oportet, pauperes ecclesiarum divitiis sustentari.

La constitución 3 se refiere a la 6 y aclara que las personas que antes de la prohibición de 1 de junio se hubiesen asociado al clericorum consortio, se vean libres de toda molestia, pero los que huyeron al clericorum numerum, después de ella, sean devueltos a la ciudad y sometidos a sus cargas (13).

La constitución 7 , de 330 , confirma los privilegios clericales dados en $C$. Th., $X V I, 2,2$ precisando que deben ser extendidos a los Donatistas.

Pero Constancio en la constitución $I I$ del mismo título, probablemente del año 342 , y refiriéndose a otra anterior que no conservamos, suprime la limitación impuesta por Constantino en la constitución 6 (de 1 de junio del año 329, como dijimos más arriba) sobre el acceso de clérigos, para aquellos que no poseen grandes bienes (qui in totum nihil possident ac patrimonio inutiles sunt) y les concede la liberación de las cargas curiales, e igualmente a sus hijos. Siete años más tarde, Constante, con la constitución 9 (349), dirigida a Severiano, Procónsul de Acaya, libera a todos los clérigos de las cargas curiales y de las funciones civiles. Sus hijos, si quisieran seguir con estos privilegios, deben perseverar en la Iglesia (14). No aparece alusión a su fortuna y hay que entender que la constitución 6 , de Constantino, había ido cayendo en olvido y la práctica llevaba a ordenar a personas de origen curial, o fortuna equivalente, si renunciaban a su propiedad, o, en algunos casos, aun sin renunciar, mientras que la ciudad no los reclamase. Esta situación se puede inferir de la constitución $C$. Th., $X I I, I, 49$, de 361 , por las que Constancio regula esta nueva situación. Que medió una constitución en el sentido anterior parece derivarse de su alusión sicut ante fuerat constitutum (C. Th., XII, 1,49$)$, que, en modo alguno, puede referirse a la constitución de Constantino $C$. Th., $X V I, 2,6$.

Conforme a la constitución 49 , del 361 , se dispone que el obispo puede conservar sus bienes e igualmente los ordenados presbíteros, diáconos y subdiáconos, si están de acuerdo la curia y el gobernador, máxime si lo pide el pueblo. Solamente los que hayan sido subrepticiamente ordenados deben entregar los bienes a sus hijos, para que éstos se sometan a la curia; de no tener hijos, a los parientes, que, sean o no curiales, deben ser sometidos a sus cargas. Si careciesen de ambos, se les permite reservarse un tercio de su fortuna, debiendo entregar a la curia los dos tercios restantes. El decreto es largo y minucioso, las prácticas fraudulentas, corrientes; las personas, influyentes. La audacia se ha incrementado. Praepositi horreorum, praepositi pacis, susceptores, magistrados elec-

13) C. Th., XVI, 2, 3, cuya subscriptio P(RO)P(OSITA) XV KAL. AUG. CONSTANTIO A. VI ET CONSTANTIO CAES. CONSS. hace decir a Mommsen, ad hanc legem: «si est anni 320, requiritur Constantino. Sed recte fortasse Seeckius hanc constitutionem, utpote explicantem eam quae legitur 16, 2, 6, reicit ad a. 326 Constantino A. VII et Constantio C. conns.», pero la corrección de GAUDEMET, 1951, 55, n. 54: C. Th., XVI, 2, 3, a Basso, Prefecto de Pretorio, y 6 a Ablavio, Prefecto de Pretorio, no pueden ser sino de 329 , fecha a partir de la que ocupan este cargo.

14) C. Th., XVI, 2, II [353 (342?)]; 9 (349). De donde se puede deducir la tendencia de que todos los ordines, collegia, etc., se conviertan en hereditarios. Sin que se pueda descartar el interés de Constante de oponer un número mayor de partidarios del concilio de Nicea a los arrianos moderados del concilio de Antioquía en 341. 
tos se hacen ordenar. Contra éstos previene a los obispos; a los gobernadores les ordena reincorporarlos a la curia (15).

c) Otros privilegios fiscales.

La constitución C.Th., XVI, 2, 8, del 343, de Constancio, dirigida a los clérigos, alude a otra u otras que no se han conservado (...(sanctionem), quam dudum meruisse perhibemini...) probablemente de Constantino; la constitución 8 concede a los clérigos y a sus esclavos la exención de collationes novas, que probablemente designe la exención de tasas extraordinarias y del hospedaje (16).

La constitución 10 del mismo título, probablemente del año 346, dirigida a todos los obispos, para estimular vocaciones sacerdotales entre sus súbditos, concede la inmunidad y libera de los munera sordida (17), collatio lustralis (negotiatorum dispendiis minime obligentur), de la contribución de bestias de carga para el transporte público ( parangararium exactio) y de la capatatio a ellos, sus mujeres, hijos y sirvientes (Quod et coniugibus et liberis eorum et ministeriis, maribus pariter ac feminis, indulgemus, quos a censibus etiam iubemus perseverare inmunes) (18).

En el año 356, el obispo de Roma Liberio, se había opuesto a condenar a Atanasio, obispo de Alejandría, y por tanto a abandonar el credo de Nicea; arrestado por el Praefectus Urbi y llevado por la fuerza a Milán, después de comparecer ante el Emperador Constancio, fue deportado a Berea, en Tracia. Estos hechos llevarían a la pérdida de la inmunidad a la Iglesia de Roma o a vacilaciones del Praefectus Urbi en su aplicación por lo que la constitución 13 aclara a Leoncio (19) que los privilegios concedidos anteriormente por Constante y Magnencio a la Iglesia y clérigos de Roma deben ser protegidos (C. Th., XVI, 2, 13 (357 MMS) (356 Seeck) MESLIN-PALANQUE, 1967, 71); posteriormente responde solemnemente al nuevo obispo de Roma, Félix (KLEINE PAULY, II, 531: Félix II antipapa, 355-358) con la decisión del consistorio, recogida en $C$. Th., $X V I, 2,14$ (357), que extiende a Occidente los privilegios concedidos anteriormente a Oriente: Exención de comparecencia a juicio (para Oriente: $X V I, 2$, 12 (355), exención de extraordinaria et sordida munera, exención de collatio lustralis, de las prestaciones del cursus publicus y no sólo para ellos sino para sus hijos y siervos (para Oriente $C$. Th., $X V I, 2,8$ (343) que fueron libres del censo, es decir de la capitatio.

Pero con todo los clérigos no quedaron satisfechos y, en el concilio de Ri-

15) C. Th., XII, 1, 49 (361). El espíritu de esta ley se repetirá más tarde: C. Th., XII, 1, 59 (364); 123 (391); 163 (399); 172 (410). BIONDI, 1952, I, 361-374.

16) C. Th., XVI, 2, 8 (343). HOSPITIUM: Se entiende aquí el derecho a ser albergado, hospedaje, introducido por Constancio a favor de los agentes civiles y extendido con regulación minuciosa por $C$. Th., VII, 8, 5 (398) a los militares. Cf. GAUDEMET, 1958, 178, y 1967, 724.

17) Una enumeración no restrictiva se encuentra en $C$. Th., XI, 16, 15.

18) C. Th., $X V I, 2,10$ [353 (320? Mommsen)]. La datación del 353 corresponde al consulado indicado. Mommsen (ad hanc legem) supuso que era una constitución de Constantino y piensa en el año 320. JONES, 1964, III, 19, n. 12, da el año 346 como probable, e igualmente GAUDEMET, 1958, 170 y 178, n. 4, por la coincidencia de un consulado conjunto de Constancio y Constante y la presencia de Constancio en Constantinopla, época del entente Constancio-Constante por el que se llega a una coexistencia entre Niceanos de Occidente y los Arrianos de Oriente (MESLIN - PALANQUE, 1967, 68 y ss.). La motivación de la ley podría haber sido el hacer más tolerable la regresión de las posturas teológicas mediante una serie de privilegios materiales. La medida fue renovada en 357 (C. Th., XVI, 2, 14).

19) Este Leoncio es Flavius Leontius 22, el mismo que meses atrás había detenido y enviado a Milán al popular papa Liberio (Amm. $X V, 7,1-10$. Cf. JONES - MARTINDALE - MORRIS, 1971, I, 503). 
mini, le piden la exención total de la iugatio de las tierras de la Iglesia y de las suyas propias (JONES, 1964, I, 118 y II, 771. GAUDEMET, 1958, 171 y 179).

Constancio, en 359 ó 360 , les concede la inmunidad para las tierras de la Iglesia, pero les niega la de las propias tierras y, teniendo ya sujeta a su lado la mayoría de los obispos, recorta las antiguas concesiones: Los clérigos permanecerán libres de los extraordinaria munera y de la collatio lustralis, si en pequeños negocios buscan su sustento, pero los que aparecieron en las listas de la anterior recaudación como comerciantes, deben atenerse a ella. Los clérigos que son possesores deberán pagar por sus tierras y por las que llevan por cuenta de otro (copiatae), y sostener y prestar todos los servicios y transportes que les correspondan. (C. Th., XVI, 2, 15).

Esta constitución que se elabora con el consejo de los obispos de Italia, Africa y España, dirigida a las partes de Occidente, ejemplifica los deseos de la Iglesia respecto al ejercicio del comercio por los clérigos mayores, así como deja entrever que se daba la práctica fraudulenta de poner las tierras a cargo de un clérigo por parte de los laicos. (GAUDEMET, 1958, 170 y 179)

Nos hemos alargado en la exposición de los privilegios concedidos a la Iglesia por Constantino y sus hijos para poner de manifiesto cómo contribuían al empobrecimiento no sólo de las curias sino del Estado.

d) Política de Juliano.

Juliano, que pretendía llevar a cabo la restauración económica del Estado Imperial, se vio en la precisión de suprimirlos, sin por ello hacer otra cosa que poner en marcha la política que en los momentos de apuro económico, de una forma u otra, harían los emperadores siguientes. Con ello no transgredía principio alguno de la Constitución del Estado, sino que suprimía privilegios, que, como favores de los príncipes anteriores, no sólo eran revocables sino que, para su mantenimiento, necesitaban una confirmación expresa del nuevo emperador (ANDREOTTI, 1930, 367). Alguno de estos privilegios, como la exención de la iugatio a las tierras de la Iglesia no volverá a aparecer posteriormente. (JONES, 1964, I, 181; GAUDEMET, 1958, 312).

El texto latino Decuriones, qui ut Christiani declinant munia, revocentur, podría prestarse a interpretación equivocada, en el sentido de que los decuriones cristianos estarían dispensados de la curia. No existen indicios para pensar así. Hemos visto que, en la legislación anterior, los privilegios eran concedidos a los miembros que habían recibido las órdenes canónicas denominadas mayores, y en algunos casos, extendidos a sus mujeres, hijos y sirvientes, pero nunca encontramos que hayan sido concedidos a los cristianos en general.

Constancio, dirigiéndose a los Antioquenos, un año antes (C. Th., XVI, 2, 16) había concedido privilegios generales a cristianos ligados con voto $y$ distinguidos por su probada virtud y oración. Pero tampoco en esta ocasión se hace con carácter general, ni por supuesto en la legislación posterior a Juliano. (DECLAREUIL, 1904, 224-327).

La exención de la curia era mal vista y considerada ilegal por los paganos (20).

20) Otros tipos de exención aceptados normalmente por los paganos eran los provenientes de la pertenencia a antiguos colegios sacerdotales, especialmente Pontífices y augures, los flámines y sacerdotes del culto imperial al terminar sus funciones anuales. DECLAREUIL, 1904, 320 y ss. 
Libanio, hablando de la situación de las curias, después de enumerar a los que se introducían en los officia y en el senado, nos dice que «había otro tipo que absorbía a los otros, que llevaba una vida de ocio y placer corporal y se burlaba de los que no seguían su mismo comportamiento». (Or., XVIII, 146-147).

En consecuencia la primera parte de eșta constitución persigue a los decuriones que habían entrado a formar parte de los clérigos cristianos (21)

e) Abrogación de las medidas de Juliano.

El realismo de la medida se pone de manifiesto al examinar la cautela con la que esta constitución es abrogada. Así Valentiniano y Valente al comenzar su reinado en común en la constitución de 12 de septiembre de 364, C. Th., XII, 1 , 59 y $X V I, 2,17$, dirigida a los Byzancenos, permiten que los curiales cristianos entren a formar parte de los clérigos siempre que transfieran sus bienes a un familiar que les sustituya o los cedan a la curia, pero prohiben absolutamente la ordenación de los plebeyos ricos, que habían sido obligados a la curia de Antioquía por Juliano. (C. Th., XII, 1, 53). Lo mismo había legislado Constancio tres años antes (C. Th., XII, 1,49$)$.

La situación de los curiales que, a pesar de las prohibiciones de los emperadores, se habían hecho ordenar, fue regulada en el 370 por Valente $(C$. $T h$, $X V I, 2,19)$, concediendo permanecer inmunes de la curia a todos aquellos que llevasen diez años ordenados. Por tratarse de una ley para las partes de Oriente favorecería a gran número de curiales influyentes. Un año después, Valentiniano concedía la inmunidad a todos los ordenados antes de su ascensión al poder, es decir con anterioridad al 364 (C. Th., XVI, 2, 21; GAUDEMET, 1958, 145; DECLAREUIL, 1904, 324, n. 3). Con esta última medida se dejan sin efecto las disposiciones del emperador Juliano al respecto.

Teodosio I, a pesar de su piedad, con un lenguaje y argumentación que recuerda los del propio Juliano, mantiene, en el año 383, la obligación de renunciar a sus propiedades para los curiales que deseen ordenarse $(C$. Th., $X I I, 1$, 104); y tres años más tarde, les recuerda que si quieren permanecer inmunes, deben poner a otro en su lugar $(C . T h ., X I I, 1,115)$ (386). Ante las quejas de Ambrosio, obispo de Milán, de que muchos sacerdotes y clérigos con más de treinta años de antigüedad habían sido sometidos a las curias, Teodosio, en el año 390, dispone que todos los sacerdotes, diáconos o exorcistas ordenados antes del 388, puedan retener su propiedad $(C$. Th., $X I I, 1,121)$. La ley no debió tener efecto y un año después insiste: Evidens etiam praecepto nostro tempus expressum est, ex quo consulatu, si qui de curialibus ad ecclesiam confugissent, omni scirent patrimonio curiae esse cededum (C. Th., XII, 1, 123 (391).

Finalmente las constituciones 163, del 399, bajo el gobierno de Arcadio para Oriente, y 172 , del 410, bajo Honorio, para Occidente, mantienen la misma doctrina. «En una palabra, la Iglesia no goza de ningún favor, pero no puede quejarse de ningún rigor excepcional. Sigue el ordenamiento general» (DECLAREUIL, 1904, 327).

21) GODOFREDO, 1665, IV, 391, por otras razones que ESSLIN, 1922, 144, n. 6, critica. DECLAREUIL, 1904, 324 y n. 3, piensa que abroga directamente $C$. Th., XII, 1, 49 (361). 


\section{Exención de la collatio lustralis}

Este impuesto establecido por Constantino y del que tenemos la primera referencia en el $C$. Th., VII, 20,2, del 320, fecha que Seeck retrasa hasta el 326, al eximir a los veteranos de este impuesto, gravaba a los negotiatores, entre los que se comprendían todas aquellas personas que vivían del ejercicio de la compraventa, incluyendo igualmente a los prestamistas y prostitutas. Como su nombre indica, era exigido al ascenso al poder y en las fiestas que celebraba cada cinco años. Exigido en un principio en oro y plata (chrysargyron), a partir del año 372 , fue exigido solamente en oro.

La recaudación de este impuesto fue lo que mayores protestas y lamentaciones levantó, según se desprende del testimonio de Libanio y Zósimo (LIBANIO, Or. XLVI; ZOSIMO, II, 28)

Las directrices de los emperadores se muestran constantes. Se precisa convenientemente aquellas ventas menores que no deben ser consideradas materia de tributación. Así las ventas que los campesinos o colonos puedan hacer de lo obtenido en sus tierras (22) o las que los veteranos puedan realizar, siempre que no excedan de 100 follis o, más tarde, de 15 sólidos (23). Médicos y profesores gozaron tradicionalmente de inmunidad. La Iglesia, en un primer momento goza hasta una cierta cantidad, limitada a 10 sólidos para Italia y 15 para las Galias; aun cuando se reconozca que con estas pequeñas transacciones se sostenga a los pobres (24). Todos los negocios que excedan estos topes, fijados por los emperadores, se verán obligados a la collatio lustralis. A medida que el patrocinium se extienda, los emperadores tipificarán este delito (C. Th., XIII, 1, 15 (386) y $21(418)$.

Juliano, mediante la constitución que nos ocupa, exime a los curiales de este impuesto, siempre que negocien por debajo de los tipos fijados: (Decuriones) et ab auri atque argenti praestatione, quod negotiatoribus indicitur, curiae immunes sint, nisi forte decurionem aliquid mercari constiterit, ita ut ordines civitatum ex huiusmodi reliquis sarcinarum, ut iam diximus, amoveantur.

Los curiales como miembros de la curia estaban sometidos al aurum coronarium, tributo en coronas de oro que las ciudades y a veces los senadores (aurum oblaticium) votaban en ocasión del advenimiento de un emperador o de los festejos celebrados en los quinquennalia. Originariamente voluntario se había hecho consuetudinario, pero todavía conservaba recuerdos de su origen triunfal (SESTON, 1942, 230; JONES, 1964, I, 430; GODOFREDO, 1665, IV, 602). La collatio lustralis se pagaba en las mismas ocasiones que el aurum coronarium y recaían ambos sobre los curiales. Juliano, en cierto modo, mantiene la legislación de Constancio, ya que la inmunidad se concede a las curias como cuerpo solidario, pero se mantiene el impuesto para aquellos decuriones que ejerciesen la profesión de negotiatores.

22) C. Th., XIII, l, 3 (361): rusticanos colonosque (senatorum); 6 (364): qui propriore rure; 8 (370): colonos rei privatae; 10 (374): colonos rei privatae ceterosque rusticanos; 12 (384): qui innocenti industria suis possessionibus innatos simpliciter vendunt; 13 (384): si per eos vernacula quaeque vendantur.

23) C. Th., VII, 20, 2 [320 MMS (326 Seeck)]; 3 [320 MMS (325 Seeck)]: 100 follis; XIII, 1, 2 [360 MMS (357 Seeck)]; VII, 20, 9 (366); XIII, 1, 7 (369) y 14 (385) 15 solidi.

24) C. Th., XVI, 2, 8 (343); 10 [353 MMS (364 Seeck)]; 14 [357 MMS (356 Seeck)]; XIII, 1, 5 (364); 11 (379): 10 sólidos en Italia e Ilírico y 15 en las Galias; 16 (399). Cfr. BIONDI, 1952, I, 370 y ss. 
Juliano, durante su estancia en Antioquía, en el famoso discurso conocido como Misopogon, en el que finge defenderse de los ataques y burlas de los Antioquenos, tan opuestos a él, pone en boca de éstos los reproches, tal vez originados por la aplicación de esta ley, que reproducimos.

«Los notables de la ciudad han sido doblemente penalizados, pues antes de tu llegada» (de Juliano) «gozaban recogiendo provechos dobles, como propietarios y comerciantes, pero hoy viven tristes, a causa de haber perdido las ganancias por una y otra parte» (JULIANO, Misopogon, 350, b).

Godofredo cree que las curias habían sido obligadas con justicia a este tributo, dado que en ellas se llevaban a cabo importantes transacciones, de trigo especialmente (GODOFREDO, 1665, V, 8). Pero Juliano, preocupado por el ordo municipalis, trata de encontrar medidas equilibradas y justas, aunque incomprendidas por su principal biógrafo que llegará a decir: maximeque municipalium ordinum, ad quorum favorem propensior, iniuste plures muneribus publicis annectabat (AMMIANO, XXI, 12, 23). Es posible que esta constitución generalice un edicto, dado en Naissos; precisamente el que habría causado el amargo y, a nuestro modo de ver, injusto reproche de Amiano Marcelino, que coincide con Libanio en el desacuerdo con las medidas tomadas respecto a los curiales, tal vez como piensa Piganiol, por su condición de tales (PIGANIOL, $1972^{2}$ (1947), 149).

Mientras que las curias pagaban el impuesto solidariamente, los grandes propietarios podían comerciar en la seguridad de que el tributo de la collatio lustralis sería pagado por todos, comerciantes o no; mientras que a partir de esta disposición, solamente los negotiatores se verían obligados a pagar personalmente este impuesto, y como decuriones, además el aurum coronarium. Todavía como possesores se verían obligados por la constitución C.Th., $X I, 16,10$, a tributar por sus tierras y a atender los munera en ella señalados (JULIANO, 1964, II, 2, Misopogon, 350 a, 173).

La exención de Constancio al clero de este impuesto si exiguis admodum mercimoniis tenuem sibi victum vestemque conquirent (C. Th., XVI, 2, 15 (359), debió de ser suprimida por esta ley, por lo menos para aquellos que no gozasen de la condición de decurión. Estos si bien obligados a la curia, estarían eximidos del mismo. Pero las medidas de los emperadores tenían escasa eficacia y ya a comienzos del gobierno de Valentiniano y Valente, tendrán que recordar que los cristianos como tales no tienen derecho al privilegio del chrysargyron $(C$. Th., XIII, 1, 5 (364) retrasada por Piganiol a 365; PIGANIOL, 1972², 151; GAUDEMET, 1958, 171; SOTOMAYOR, 1979, 177).

Finalmente se cierra esta parte de la constitución perdonando las cantidades adeudadas de este impuesto (25).

La insolvencia de las ciudades hará que esta medida de remisión de deudas

25) Es sin duda el estado ruinoso de las ciudades lo que le lleva a permitir la remisión de atrasos, al tiempo que en otra parte de este conjunto de medidas prohibe tanto establecer nuevos impuestos como la remisión de los establecidos. C. Th., $X I, 16,10$ (13 marzo 362): «Nihil Provincialibus indici sine nostra scientia fas est neque rursus ex his quae sunt indicta referri.» (El subrayado es nuestro.) La razón de prohibir la remisión de lo debido nos la da Amiano: «Denique id eum ad usque imperii finem et viate scimus utiliter observasse, ne per indulgentias, quas appellant, tributariae rei concederet reliqua. Norat enim hoc facto se aliquid locupletibus additurum, cum constet ubique pauperes inter ipsa indictorum exordia solvere universa sine laxamento compelli.» AMM. XVI, 5, 15. 
atrasadas sea más frecuente, en las constituciones del Codex Theodosianus, que lo que sería de desear.

\section{La huida al patronazgo de un potens}

La tercera y última parte de esta constitución presenta de un modo claro, por primera vez, un tipo de evasión de las cargas fiscales, que aparece perseguido a lo largo de la segunda mitad del siglo IV y durante el siglo $\mathrm{V}$ en las constituciones de los emperadores (C. Th., XI, 24, 1 (360); 2 (370) (386?); 3 (395); 4 y 5 (399) y 6 (415). Todas referidas a Oriente, especialmente a Egipto.

En el año 318, una constitución de Constantino $(C$. Th., $X I I, 1,6)$ castigaba con gran dureza al decurión que se casase con una mujer esclava, deportándolo a una isla, y disponiendo que sus bienes muebles y esclavos fuesen confiscados, y los rústicos, si no tenía hijos o parientes que le heredasen, entregados a la curia; la mujer sería destinada a las minas. La misma pena alcanza al actor o procurator del fundus que consienta tal «azote» y no lo impida o denuncie. Si se trata del dominus perdería el fundus, esclavos, ganados y cuantos aperos se necesitan para su cultivo, que pasarían al fisco, si el hecho tuviese lugar en el campo; o la mitad de todos sus bienes, si en la ciudad.

Las penas son excesivas, si solamente se tratase de reprimir uniones desiguales entre un decurión y una mujer esclava, que aunque indignas y fuente de esclavitud para los hijos nacidos del contubernium, no están prohibidas por las leyes, como aparece en el preámbulo mismo de la constitución. Se trata, y de ahí la severidad de las penas, de impedir que un miembro de la curia pase con sus bienes a depender del potens, dueño de la esclava, y de este modo el consortium curiale quede debilitado, pues los hijos nacidos del contubernium no son aptos para la curia, por su condición servil. De ahí que la confiscación de bienes por la curia se dé únicamente a falta de heredero o pariente que le sustituya en la curia. También podría tratarse de impedir que el curial se beneficiase del patronazgo de un potens para evadir la persecución de la curia o del Estado.

De modo paralelo en esta tercera parte de la constitución se prohibe y castiga quoniam ad potentium domum confugisse quosdam relatum est Curiales, $u t$ tam foeda perfugia prohibeantur, multam statuimus, ut per singula capita singulos solidos dependat, qui ad potentis domum confugerit, et tantumdem qui receperit multae nomine inferat: Nam si servus inscio domino susceperit, capite punietur et ingenuus qui invito patrono hoc fecerit deportabitur.

La constitución de Juliano condena al decurión a una multa de un solidus por caput e igualmente al encubridor, si era libre; si esclavo, y sin saberlo el dueño, sufría la decapitación; finalmente si el encubridor era ingenuus, un colono, y contra la voluntad del patrono, era condenado a la deportación, pena ésta que suponía el exilio y confiscación. La gravedad de las perras, tanto en el caso de la constitución $C$. Th., XII, $1,6(318)$ de Constantino, como en la 50 (362) de Juliano, hace pensar que se trata de salir al paso a nuevos modos de evitar la curia. En el primer caso porque los hijos de esclava no eran aptos para la curia y en el segundo porque con el patrocinium del potens se evitarían las obligaciones de la curia.

Observemos que las penas de los dos emperadores están diferenciadas y 
graduadas pro qualitate personarum, si bien son diferentes y tal vez más benignas las de Juliano. Tal evolución acorde con la humanización del derecho que de Constantino a Justiniano se produce, bien por influencia del estoicismo o del cristianismo o de ambos a la vez. Pero la menor severidad de la constitución de Juliano puede deberse a una orientación económica. La deportación del curial es sustituida por la satisfacción de una multa. De este modo tanto él como sus tierras seguirán sirviendo a los intereses de la curia, sin que se disminuya el rendimiento de las tierras siempre mayor al ser cultivadas por el propietario. Al mismo tiempo el fisco ingresa una cantidad importante en oro en concepto de multa.

Si se calcula que el término medio de la propiedad de un curial es de 150 iugera, y el mínimo exigido para pertenecer a la curia son 25 iugera, la cuantía de las multas oscilaría en torno a los 300 sólidos, con un mínimo de 50 , cantidades importantes para la época, si se tiene en cuenta que en un sólido se evaluaba el costo de la manutención de un niño durante un año (JONES, 1964, II, 738; CHAO, 1978, 45-46).

Notemos igualmente que en los casos de deportación y consiguiente confiscación, las tierras pasarían a la propiedad del emperador o res privata que normalmente eran arrendadas, frecuentemente a las mismas ciudades, aunque la política de los emperadores es cambiante, probablemente en función de la capacidad del curial de resistirse a pagar los alquileres de tierras con diversos subterfugios (C. Th., $X, 3)$.

Los términos confugisse y perfugia señalan un nuevo tipo de fugitivus, el curial. Bajo la República y el Alto Imperio este término designaba exclusivamente al esclavo que se había escapado de su dueño. En caso de captura era condenado a la devolución a su dueño o a un brutal castigo, generalmente la muerte. El término suscitaba entonces los terrores de las guerras de esclavos, el recuerdo de Espartaco; pero en el Bajo Imperio las constituciones lo emplean en un sentido mucho más extenso. Fugitivi son los coloni o propietarios que abandonan las tierras en las que han sido inscritos, o que se ponen a trabajar en las tierras de otro colono o propietario; los corporati de los officia urbanos y los curiales que, de uno u otro modo, abandonan las curias.

Estos casos de evasión aumentan por millares a medida que avanza el siglo IV, y son reprimidos por las constituciones con severidad creciente (26).

Otro tipo de fugitivi lo constituirán los desertores, soldados ya enrolados, o plebeii que, temiendo ser enrolados en el ejército, se incapacitan con la mutilación, en general, de los dedos de la mano derecha (práctica muy extendida en el Bajo Imperio) (GAUDEMET, 1951, 74 ss; PIGANIOL, 1972², 397 y 398; LIBANIO, Or. XLVII).

En la misma época se define otro nuevo tipo de delincuente, el ocultator; para él se fijan penas acordes a su clase social y a la del individuo que acoge; en general, se trata de potentiores, clarissimi o altos funcionarios militares y civiles, pero otras veces son curiales (JONES, 1964, II, 776).

La gravedad de las penas indica el peligro que encerraban estas «evasiones

26) Sobre el patronato y su evolución: JONES, 1964, II, 775 y ss. GAUDEMET, 1967, 712 y ss., con bibliografía. LIEBENSCHUETZ, 1972, 192-208, especialmente 200 y ss. 
sociales» para el Estado Imperial y cómo se multiplicaban y extendían a diversos ordines (27).

El Codex Theodosianus no recoge constituciones dirigidas a las partes de Occidente. Este hecho no supone que la práctica allí fuese rara en la época en la que en Oriente el patrocinium se desarrolla, sino más bien que, dado el carácter que la gran propiedad había adquirido en estas regiones del Imperio, los grandes propietarios no la verían con malos ojos, pues les favorecía, y la significación de las ciudades seŕía menor. Sin embargo, en el siglo siguiente, Salviano atestigua esta práctica en Occidente, al denunciar que tuitio parentum mendicitate pignorum comparatur (28).

\section{AMMIANUS MARCELLINUS}

\section{FUENTES}

1978. Rerum gestarum libri qui supersunt, edidit Wolfgang Seyfarth, adiuvantibus Liselotte JacobKarau et Ilse Ulmann, 2 vols., Teubner.

CODEX THEODOSIANUS

1665. Codex Theodosianus cum perpetuis commentariis Jacobi Gothofredi. Opus postumum rec. et ordinavit ad usum Codicis Iustinianei Antonius Marvilius, Lugduni.

1971. (Reimp.) Theodosiani libri XVI cum constitutionibus Sirmondianis, edidit adsumpto apparatu P. Krueger, Th. Mommsen, 2 vol. in 3. Berlín.

CORPUS IURIS CIVILIS

1963. (Reimp.) Vol. I. Institutiones, rec. P. Krueger; Digesta, rec. Th. Mommsen, retract. P. Krueger. Vol. II. Codex Iustinianus, rec. et retract. P. Krueger. Berlín.

IULIANOS

1924-1964. L'Empereur Julien. Oeuvres complètes. Paris.

1924. Lettres et fragments, ed. J. Bidez, T. I, 2.

1932. Discours de Julien César, ed. J. Bidez, T. I, 1.

LIBANIOS

1963. Discours de Julien Empereur, ed. G. Rochefort, T. II, 1.

1969. Selected Works, with an engl. trans., introd. and notes by A. F. Norman, 3 t. especialmente t. ZOSIMO

I: The Julianic Orations. Londres.

1971-1979. Histoire nouvelle, Texte établi et tradui par F. PASCHOUD. Paris.

\section{BIBLIOGRAFIA}

ANDREOTTI, R. 1930. «L'opera legislativa ed amministrativa dell'imperatore Giuliano», Nuova Rivista Storica, $X V I, 342-383$.

ARCE, J. J. 1975. a) Estudios sobre las fuentes literarias, epigráficas y numismáticas para la historia del Emperador $\mathrm{Fl}$. Cl. Juliano. Granada (Tesis de doctorado inédita.)

- $\quad$ 1975. b) Estudios sobre las fuentes literarias, epigráficas y numismáticas para la historia del Emperador Fl. Cl. Juliano. (Resumen de Tesis doctoral.) Universidad de Granada.

BIDEZ, J. 1965. (Reimpresión.) La vie de l'empereur Julien. París.

BIONDI, B. 1952. Diritto Romano Cristiano. 3 vol. Milán.

BOWERSOCK, G. W. 1980. Julian the Apostate. 2. ${ }^{a}$ ed. (1978). Cambridge, Massachusetts.

27) GAGE, 1971, 415 y ss. Cfr. etiam $C$. Th., V, 17; de fugitivis, inquilinis et servis; C. Th., XI, 24: De patrociniis vicorum, y VII, 18: de desertoribus et ocultatoribus.

28) JONES, II, 778. SALVIANO, De Gubernatione Dei, 5,8 y 38-45, donde describe el patrocinium con tintas negras. 
BROWNING, R. 1975. The emperor Julian. Londres.

CHAO, J. J. 1978. «El derecho penal en las constituciones del Emperador Fl. Cl. Juliano conservadas en el Codex Theodosianus». ITEM, Revista de Ciencias Humanas, 4, 33-53.

CHASTAGNOL, A. 1969. Le Bas Empire. París.

ENSSLIN, W. 1922. «Kaiser Julians Gesetzgebungswerk und Reichsverwaltung». Klio, XVIII, 104-199.

FONTAN, A. 1974. Humanismo romano. Barcelona.

GAGE, J. 1971. Les classes sociales dans l'Empire Romain. París.

GAUDEMET, J. 1951. "Constantin et les curies municipales». Iura, Rivista internacionale di Diritto romano et antico, II, 44-75.

- 1958. L'Eglise dans l'Empire Romain (IV et V siècles). París.

- 1967. Institutions de l'Antiquité. París.

JONES, A. H. M. 1964. The Later Roman Empire 284-602. A social economic and administrative survey. Oxford.

JONES, A. H. M. - MARTINDALE, J. - MORRIS, J. 1971. Prosopography of the Later Roman Empire. Vol. I. Oxford.

LIEBESCHUETZ, J. H. W. G. 1972. Antioch: City and Imperial Administration in the Later Roman Empire. Oxford.

MATROYE, F. 1928. "Les patronages d'agriculteurs et de "vici" au IV siècle». Revue d'Histoire et Droit Francais et Etranger, 7, 201-248.

MESLIN, M. - PALANQUE, J. R. 1967. Le Christianisme Antique. París.

PIGANIOL, A. 1972. L'Empire Chretien 325-395. París. 2. a edición.

REMODON, R. 1964. La crise de l'Empire Romain de Marc Aurele à Anastase. París.

SOTOMAYOR, M. - GONZALEZ, T. - LOPEZ DE OSABA, P. 1979. Historia de la Iglesia en España. I. La Iglesia en la España romana y visigoda. Dirigida por R. Villaoslada. Madrid.

ZIEGLER, K. - SONTHEIMER, (edts.) 1966. Der Kleine Pauly. Lexicon der Antike auf der Grundlage von Pauly's Real-encyclopädie der Classischen Altertumswissenschaft. 5 vols. Stuttgart. 